\title{
A política externa estadunidense no atual quadro político sul-americano
}

\section{Luiz Fernando da Silva*}

Resumo: A tese central que procuramos explorar nesse artigo é de que o presente quadro político sul-americano tem exigido do imperialismo estadunidense uma redefinição estratégica, no sentido de neutralizar, debilitar e, se possível for, destruir experiências/ tendências políticas regionais que não se alinham à sua política externa. Sob a máscara da defesa da democracia e do argumento de que as "políticas orientadas para o mercado" latino-americano correm risco, em razão de questôes como delinquiência, crime organizado internacional, narcotráfico mundial e terrorismo global, a estratégia global do imperialismo estadunidense passa então a definir uma nova doutrina de guerra preventiva que justifica a utilização do poder bélico contra qualquer país, em nome de sua própria defesa. No cerne da questão o que - de fato- está em pauta é a defesa (e reprodução) dos interesses de suas corporaçóes multinacionais e capital financeiro, por meio do confisco internacional de ativos lucrativos, tais como financeiros, energéticos, comunicacionais e de recursos naturais, ademais do domínio de mercados locais.

Palavras chave: Militarização-América Latina, Imperialismo-estadunidense, Política externa-Estados Unidos.

RESUMEN: La tesis central que intentamos investigar en este artículo es que el presente escenario político sudamericano ha demandado del imperialismo estadounidense una redefinición estratégica, en el sentido de neutralizar, debilitar y, si es posible, destruir experiencias/tendencias políticas regionales no alineadas a su política externa. Desde la máscara de la defensa de la democracia y del argumento de que las "políticas orientadas hacia el mercado" latinoamericano están en riesgo, por problemas que van desde la

Universidade Estadual Paulista Júlio de Mesquita Filho, unesp, São Paulo, Brasil (lf-silva@faac. unesp.br). 
"delincuencia" — en México_- el terrorismo global, el crimen organizado internacional hasta el narcotráfico mundial, la estrategia global del imperialismo americano entonces pasa a establecer una nueva doctrina de guerra preventiva que justifica la utilización del poder bélico contra cualquier país, en nombre de su propia defensa. En el centro de la cuestión lo que - de hecho - está en el orden del día es la defensa (y reproducción) de las ganancias de sus corporaciones multinacionales y capital financiero, por medio de la incautación internacional de los activos de intereses, tales como financieros, energéticos, comunicacionales y recursos naturales, además del dominio de mercados locales, más allá de facilitar la huida de capitales entre otros.

Palabras Clave: Militarización-Latinoamérica, Imperialismo estadounidense, Política externa-Estados Unidos.

ABSTRACT: The central thesis that we aim to survey in this paper is that the present South-American political scene has required of the American imperialism a strategical redesign, in the sense of the neutralization, weakening and, if it is possible, destruction of regional political experiences/tendencies not aligned to its foreign politics. Under the mask of the defense of democracy and beneath the argument that Latin American "market oriented politics" are at stake, due to questions that goes back from the "delinquency" —in Mexico — , the global terrorism, the organized international crime up to the worldwide drug traffic, the global strategy of American imperialism then sets up the definition of a new doctrine of preventive war that justifies the utilization of hard power against any country, in the name of its own defense. At the heart of the question what - actually _ is in the agenda is the defense (and reproduction) of the benefits of its multinationals corporations and financial capital, by means of the international subtraction of profitable assets, such as financial, energetic, communicational and natural resources, in addition to the domination of local markets, beyond facilitating capital flee amongst others.

Key words: Militarization-Latin America, American Imperialism, Foreign Politics-United States. 
política externa estadunidense preserva sua tradição ostensiva sobre
a América Latina. Os EU mantêm-se presente e hostil na região, como
historicamente sempre esteve. Assim foi com os governos norte-
americanos anteriores, como também assim é na atual Administração Barack Obama.

Essa tradição conformou um padrão de política externa que se desenvolveu em três períodos históricos ${ }^{1}$ distintos apreendidos como tendência: a) de 1776 a 1945, quando os Estados Unidos passaram da condição de país periférico e se projetaram internacionalmente; b) de 1947 a 1989 período marcado pela ascensão e disseminação da hegemonia estadunidense, constituição e término da Guerra Fria, e colapso do Leste Europeu; c) de 1989 até os dias atuais, passando pela Guerra do Golfo (1991), os atentados ocorridos em 11 de setembro de 2001, chegando à vitória de Barack Obama, em 2008.

Com a discriminação desses períodos podemos entender que existe mais continuidade do que mudança na política externa estadunidense. Embora ocorram adaptações aos novos cenários internacionais, especialmente após o período de Guerra Fria, as diretrizes da atual ação política externa dos Estados Unidos remontam à tradição constituída. Nesse marco verificamos que os temas

1 Nessa divisão em períodos, em linhas gerais acompanhamos Cristina Soreanu Pecequilo em seu livro A política externa dos Estados Unidos. Continuidade ou mudança? Porto Alegre, UFRGS, 2003. Pecequilo considera que entre 1776 e 1945 constituiu-se de fato uma tradição que determinou as formas de atuação dos Estados Unidos em suas relações externas. A divisão dos períodos acompanha os acontecimentos-chave da evolução das relações internacionais estadunidense. Em relação aos fatos que marcaram o período de cristalização da tradição de relações externas, podemos citar: a Independência Americana (1776) e o processo de consolidação do regime político; a Doutrina Monroe (1824); a expansão territorial com a ocupação e anexação de territórios ao Oeste dos EU e anexação de parte do México (1845-1848); o Destino Manifesto (1850); o boom econômico pós-Guerra da Secessão (1861-1865) e as suas conseqüências; a Guerra Hispano-Americana (1898); intervenção e ocupação político-militar em países da América Central e Caribe (1898-1933); EU declaram guerra à Alemanha (abril de 1917) e entram na Primeira Guerra Mundial (1914-1918); a crise do período entre-guerras e a Segunda Guerra Mundial (1939-1945). Em cada um desses eventos, os interesses e as prioridades definidos pelos Estados Unidos foram responsáveis pela conformação de um certo tipo de comportamento internacional que deu origem às raízes da política externa norte-americana, por nós definida como cristalização de um padrão histórico. 
centrais de sua agenda guardam as concepções, necessidades e preocupações configuradas ao longo de sua história: preservação da liderança estadunidense e da estabilidade mundial por meio de uma posição de proeminência, impedindo a emergência de hegemonias regionais; promoção, defesa e universalização dos valores da democracia liberal e do livre mercado; combate aos inimigos internacionais, no caso contemporâneo o narcotráfico, o terrorismo internacional e aos governos não alinhados à agenda estadunidense. Em outros termos, tais diretrizes podem ser encaradas como uma tradução dos interesses nacionais dos Estados Unidos, visando garantir a posição e segurança de suas corporações multinacionais industriais e financeiras.

Como instrumento central para a defesa e reprodução dos interesses de suas corporações, a política externa estadunidense constituiu-se como alicerce fundamental para a expansão dos interesses de suas classes dominantes. Serviu como meio de confiscação territorial, financeiros e energéticos, apropriação de recursos naturais, além de materializar-se como suporte essencial para o domínio dos mercados locais e facilitador da fuga de capitais. A acumulação e a concentração de riquezas e sua transferência a bancos e corporações multinacionais (CMN) definem a natureza imperialista das relações entre EU e América Latina. Essa política imperialista desenvolveu-se por meio de três instrumentos centrais. ${ }^{2}$ Estado imperialista, Corporações Multinacionais e Instituições Financeiras Internacionais. Desses instrumentos consideramos, tal como Ayerbe, ${ }^{3}$ que se desdobram modalidades de intervenção que se integram e tem como objetivos: a abertura dos mercados externos, assistência a países em desenvolvimento que compartilham e se aproximam dos valores estadunidenses, e intervenção nas regiões em processo de colapso ou que sofram ataques terroristas.

Diversos fatos políticos ocorridos na última década servem-nos para ilustrar que as relações entre EU e países latino-americanos seguem um padrão histórico: a assinatura do Plano Colômbia em 2000 e a sua renovação em 2009; golpe

2 James Petras, "La economía política de la política exterior de Estados Unidos para América Latina", em Osal, núm. 17, maio-agosto, 2006, p. 290.

3 Luis Fernando Ayerbe, Los Estados Unidos y la América Latina. La construcción de la begemonía, La Habana, Casa de las Américas, 2001, p. 43. 
político fracassado na Venezuela (2002); intervenção militar no Haiti com as "forças da paz" (MINUSTAH) desde $2004^{4}$ e a ocupação militar dos EU no Haiti (2009), como ajuda humanitária, após a tragédia do terremoto no país; tentativa de desestabilização política do governo Evo Morales em 2008; Plano MéxicoIniciativa Mérida (2008); reativação da IV Frota marítima que percorre as águas do Caribe e do Atlântico (2008); o acordo com o governo do Panamá para os EU reinstalar suas bases militares no Panamá (2009); golpe civil-militar que depôs o presidente de Honduras Manuel Zelaya (2009); a assinatura do acordo militar com o Brasil (2010) e a Costa Rica (2010).

No presente texto nos detemos principalmente nos aspectos da política de militarização presente no Estado imperialista estadunidense em sua relação com os governos sul-americanos. A tese central que procuramos explorar no presente artigo é que o quadro político atual sul-americano no final do século xx e início do xXI tem exigido do imperialismo estadunidense uma redefinição estratégica, no sentido de neutralizar, debilitar e, se possível, destruir experiências/tendências políticas regionais que não se alinham automaticamente à sua política externa. Essa política, por sua vez, mantém traços intervencionistas que se apresentaram ao longo da história daquele país.

\section{Os DiAgNósticos do DePARTAMENTO DE Estado dos EU SOBRE A REGião}

A avaliação estadunidense sobre a região classifica os governos como "confiáveis" e "não confiáveis", em razão do grau de alinhamento à sua política externa. A avaliação sobre esse quadro político é relativamente nítido para o imperialismo estadunidense. A ex-secretária de Estado, Condoleezza Rice, diante da ascensão dessas novas forças políticas na região, considerava que o importante não era a origem político-ideológica, mas "uma questão de bom governo", respeitada a livre iniciativa, o sistema pluripartidário e colaborando com os Estados Unidos nos

4 Em realidade, as intervenções militares estadunidenses no Haiti se estendem dramaticamente na história. Na década de 1990, o militarismo norte-americano manteve-se no país em corpo e alma no período entre 1993-1996, por meio de cerceamento das águas haitianas e a partir de 1994 com ocupação militar. Possivelmente, no século xx, Haiti, Panamá e Honduras tenham sido os países que sofreram o maior número de investidas diretas do imperialismo estadunidense. 
assuntos hemisféricos. ${ }^{5}$ Ainda de acordo com Rice, os EU trabalhariam com todos os governos de esquerda ou de direita latino-americanos, contanto que se comprometam com princípios e práticas relacionados à democracia e à liberdade econômica.

A posição estadunidense pode ser verificada também no Informe ao Comitê de Inteligência do Senado dos EU, em dezembro de 2009. ${ }^{6}$ Ao enfocar a região latino-americana considera que a Venezuela, Bolívia e Nicarágua caminham para um modelo econômico e político autoritário e centralizado. Hugo Chávez e seus aliados mais próximos (Evo Morales e Rafael Correa) rechaçariam continuamente as iniciativas dos EU na região, no sentido de estabelecerem a colaboração para o livre-comércio e a cooperação contra o narcotráfico e o terrorismo. Além disso, esses países se recusam a treinamentos militares conjuntos, como também rejeitam iniciativas de segurança e programas de assistência junto aos EU.

Chávez aproximou-se de atores extra-regionais, como o caso da Rússia, Irã e China, por meio de relações políticas, econômicas e de segurança. A Rússia, por exemplo, assinou contratos com o governo venezuelano sobre inversões de capital na Faixa Petrolífera de Orinoco para extração de petróleo, além disso negociou cerca de seis bilhões de dólares em armas, helicópteros, tanques, transportes blindados e mísseis antiaéreos, nos últimos cinco anos. Em final de 2008, navios de guerra e aviões bombardeiros russos circularam nas costas marítimas da Venezuela, respondendo ao convite do governo venezuelano. Essas manobras militares envolvendo as duas forças navais foram consideradas como inconcebíveis pelo Departamento de Defesa estadunidense (DEA) em termos de segurança no Mar do Caribe. Mas o fato é que essas manobras navais foram uma resposta às manobras navais dos EU na região, por meio da reativação da IV Frota Marítima.

A posição norte-americana é manter isolado o governo venezuelano, inclu sive cercá-lo política e militarmente na região e debilitá-lo internamente diante

5 Condolezza Rice, Resources for transformational diplomacy, Washington, D. C., Statement Before the Senate Appropriations Subcommittee on Foreign Operations, 10 maio, 2007. En http://www.state.gov/secretary/rm2007/84645.htm.

6 Cfr. El Nacional, 3 de fevereiro, 2010, p. 9. 
da população, investindo no crescimento da oposição política liberal no país. O governo venezuelano não se submete ao alinhamento político com os EU e procura estabelecer alternativas econômicas e novas parcerias comerciais, além de manter uma radicalização discursiva de forte conteúdo anti-estadunidense. Por outro lado, a questão central para os EU não se localiza na alternativa econômica e política de cunho socialista que, porventura, o Governo Chávez tenha adotado. A postura ofensiva dos EU deve-se muito mais ao fato de que a Venezuela é responsável por cerca de 15\% do petróleo importado pelos EU, além do país possuir a maior reserva petrolífera não explorada do planeta, que é a Faixa Petrolífera de Orinoco. O fato novo é que esse governo negocia com outras potências capitalistas como Rússia, China, Irã e países europeus. Isso sem dúvida diminui a área de influência econômica estadunidense.

De maneira semelhante, e talvez mais intensa, o Brasil desenvolve esforços no sentido de ampliação de suas relações comerciais fora da relação subordinada aos EU, mas com uma diferença básica: a diplomacia brasileira aceita a coordenação estratégica estadunidense na política contra o narcotráfico, o terrorismo e as campanhas de ajuda humanitária, e participa de manobras navais conjuntas. ${ }^{7}$ Ou seja, no caso específico brasileiro, ocorre uma integração ao conceito de novo paradigma de cooperação regional. É justamente essa condição que o Governo Chávez tem sistematicamente rejeitado.

Para o diretor da Inteligência dos EU, Dennis Blair, a democracia e o livre mercado latino-americano correm risco por problemas que vão desde a delinqüência no México até o populismo na Venezuela e na Bolívia. Além dos cartéis do narcotráfico ${ }^{8}$ e os crescentes delitos violentos, em países como Venezuela,

Nos exercícios militares conjuntos envolvendo forças armadas dos países da América Latina e Caribe, realizados entre 2007 e 2010 na área do Grande Caribe, o Brasil participou em cinco missões de exercícios militares conjuntos. É o que podemos concluir a partir do levantamento realizado pela pesquisadora Ana Maria Esther Ceceña e outros, com resultados apresentados no livro El Gran Caribe. Umbral de la geopolítica mundial, Quito, Fedaeps/Observatório Latinoamericano de Geopolítica, 2010.

8 A partir das administrações republicanas da década de 1980, ocorreu uma grande mudança no combate ao tráfico de drogas nos EU. De problema interno de repressão policial transformouse em tema de política externa, no qual a participação das Forças Armadas em operações fora 
Bolívia e Nicarágua foram eleitos governos que estariam avançando para um modelo político e econômico autoritário e estatista e que se unem contra a política estadunidense na região. Ainda segundo Blair, o presidente venezuelano Hugo Chávez estabeleceu-se como um dos principais detratores internacionais dos Estados Unidos, condenando a democracia liberal e o capitalismo de mercado. ${ }^{9}$ Ressaltam-se claramente a defesa do capitalismo de mercado e o que seriam os interesses estadunidenses.

Mas na outra ponta não é possível considerar as afirmações dos EU sobre a expansão do terrorismo na região, como no caso da tríplice fronteira, onde estariam localizadas bases da Al Qaeda e outras redes terroristas. Essas suposições que associam o fenômeno do crime organizado internacional, situação visível, palpável e cotidiana para as populações dos países latino-americanos, às questões de ordem política são de fato grosseiramente aproximadas e confundidas.

\section{A ATUAL CONFIGURAÇÃO POLÍTICA SUL-AMERICANA E A GEOPOLÍTICA ESTADUNIDENSE}

Longe das justificativas em torno dos novos inimigos regionais à democracia e à liberdade, o que de fato se encontra nas iniciativas de militarização regional é a estratégia de dominação sobre os recursos energéticos, hídricos e minerais concentrados na região. Para isso, é necessário que os governos da região mantenham um alinhamento exclusivo e automático à política externa estadunidense. Hugo Chávez é concebido por essa razão como símbolo que expressaria as ameaças de desestabilização regional: detrator dos EU, opositor da democracia liberal e do capitalismo de mercado e, o que é demais significativo, "opositor das políticas e interesses estadunidenses na região".

do país começou a ser discutida. Na Administração Reagan, para reduzir os custos políticos internos da repressão mais efetiva ao consumo, a ênfase repressiva foi deslocada para as regiões produtoras. No âmbito regional foram assinados convênios bilaterais que viabilizaram a participação de assessores militares dos Estados Unidos e da Departamento de Estado Americano no treinamento das forças de segurança na Bolívia, no Peru e na Colômbia. Vide Alain Delperiou e Alain Labrousse, El Sendero de la cocaina, Barcelona, Laia, 1988; Thiago Rodrigues, Narcotráfico:uma guerra na guerra, São Paulo, Desatino, 2003.

9 Dennis Blair, "Advierten que populismo de Chávez es una amenaza para la región", en El Nacional, 3 de fevereiro, 2010, p. 9. 
A atual configuração política sul-americana apresenta-se com governos que surgiram como forças políticas de oposição a governos anteriores que implementaram políticas neoliberais. Em decorrência dos ajustes estruturais ${ }^{10} \mathrm{da}$ década de 1980 e 1990, aprofundou-se o descontentamento político de distintos grupos, camadas e classes sociais - camponeses, assalariados industriais, camadas assalariadas médias, trabalhadores desempregados, pequena burguesia e frações burguesas- que se tornou um dos principais catalizadores eleitorais para a vitória das candidaturas antineoliberais em países como Venezuela, Brasil, Argentina, Bolívia, Uruguai, Paraguai e Equador. Nesses países os governos na cionais eleitos na última década expressaram uma crítica às propostas neoliberais

${ }^{10}$ Como ajustes estruturais, consideramos as reformas econômicas ocorridas na América Latina, desde a década de 1980, direcionadas principalmente pelo Fundo Monetário Internacional (FMI), com o argumento de resolução do problema da "crise da dívida externa" que os países latinoamericanos atravessavam, em razão do volume de endividamento externo realizado por esses países em períodos anteriores. A ingerência do Fundo Monetário Internacional (FMI), na renegociação desse endividamento, significou a subordinação das políticas econômicas desses países, ao longo daquela década ("década perdida"). O alcance dos ajustes estruturais nessa parte do continente tiveram profundas e drásticas consequiências sociais e como trouxeram saldos positivos para o Capital, em especial capital financeiro. A base na qual podemos situar nessa perspectiva encontra-se no que ficou conhecido como Consenso de Washington, encontro realizado na capital estadunidense, em novembro de 1989, que teve como objetivo avaliar as reformas econômicas que vinham sendo implantadas na região. O título do encontro era sugestivo: "Latin American ajustment: How much has happended?" (Ajuste latino-americano: Quanto já ocorreu?"), organizado pelo Institute for International Economice, funcionários do governo norteamericano e dos organismo financeiros -Banco Mundial (FMI), Banco Interamericano e Desenvolvimento- especializados em assuntos latino-americanos. Consenso de Washington, na realidade, foi um marco dessas políticas que já eram adotadas, e implicou uma padronização de ajustes estruturais que se seguiram na década de 1990. Os 10 pontos da "cartilha", que saíram do encontro, foram os seguintes: cortes nas despesas com políticas sociais e investimentos, com o objetivo de "equilibrar" o orçamento estatal; prioridade ao pagamento de juros das dívidas externas e interna, nas despesas públicas; reforma fiscal; flexibilização do mercado financeiro para a presença de bancos internacionais e eliminação de restrições ao fluxo de capital especulativo internacional; equiparação moedas nacionais ao dólar; eliminação das restrições ao investimento estrangeiro; programa de privatizações; desregula-mentação de atividades estratégicas (mineração, transporte, prospecção) e das relações trabalhistas (reformas); nova lei de patentes, de acordo com exigências internacionais. Luiz Fernando da Silva, "Ajustes neoliberais e lutas sociais: estratégias políticas na América Latina", em Marxismo Vivo. Revista de Teoria e Política Internacional, núm. 13, 2006, pp. 8-14. 
e apoiavam-se em setores importantes de movimentos sociais e partidos de esquerda, inclusive apoiaram-se em frações da burguesia.

Em seus traços mais destacados podemos verificar que são governos que (a) emergem da descrença popular com as instituições estatais, corroídas pelo período neoliberal; (b) constituíram base social e política em significativos movimentos sociais (sindical e popular) e partidos de esquerda; (c) no caso argentino e venezuelano, resultam de profundas crises institucionais que levaram a levantes populares; $(d)$ constituíram amplas frentes políticas, no sentido de coalizão entre setores do Capital e representações políticas de esquerda e movimentos sociais, (e) as frações do grande capital mantiveram-se hegemônicas no bloco no poder de Estado.

Esses recém governos ao nosso entender não têm um caráter anticapitalista nem antiimperialista em geral, mas estabeleceram um relativo distanciamento em relação à política externa estadunidense. São governos enquadrados na ordem econômica e financeira internacional, abertos para empresas transnacionais, em alguns casos com traços ou pretensões de capitalismo nacional. Diferente dos governos orientados por políticas neoliberais em sua radicalidade, ou seja, reduzindo ao mínimo as política sociais, os atuais governos desenvolveram algumas políticas estatais compensatórias e, sobretudo, ampliaram suas relações comerciais com países do bloco europeu, asiático e do Oriente Médio. Nesse sentido, a centralidade nas relações comerciais com os EU foi reduzida relativamente. Esta nova condição política e econômica na região vem afetando os interesses dos monopólios estadunidenses. É esse o fenômeno que, em realidade, expressa a frase "opositor dos interesses estadunidenses na região" e que de certa maneira é sintetizada na figura de Hugo Chávez.

\section{O IMPERIALISMO ESTADUNIDENSE, CONTINUIDADE E REDEFINIÇÃO GEOPOLÍTICA}

As iniciativas diplomáticas e militares estadunidenses contemporâneas estão sintetizadas na expressão "um novo paradigma de cooperação regional" do exsecretário de Estado Adjunto para Assuntos do Hemisfério Ocidental, Thomas Shannon. Esse paradigma refere-se aos programas de segurança integrados entre os governos regionais que ultrapassam o âmbito nacional e projetam-se em um 
sistema interligado estendendo-se desde os Andes até a fronteira sudoeste dos Estados Unidos. ${ }^{11}$ É a projeção de uma arquitetura concebida para proporcionar uma barreira de segurança contra o narcotráfico, o crime organizado, a insurgência e o terrorismo, envolvendo as diversas forças de segurança dos países latinoamericanos. As "forças de paz" (MINUSTAH) no Haiti servem-nos como exemplo dessa forma de cooperação regional, como também os exercícios navais que ocorrem no Atlântico e Caribe, como as operações Panamax. Também faz parte dessa concepção integrada de segurança o Plano Colômbia e o Plano México.

O plano geral das posições militares estadunidenses, como analisa Ceceña, ${ }^{12}$ responde à estratégia de "dominação de espectro total". Por um lado, esse plano criaria cercos ou zonas privilegiadas de acesso aos recursos naturais estratégicos e, por outro lado, buscaria intimidar, controlar, penetrar e desmobilizar ou destruir qualquer oposição a esses objetivos. O controle militar do grande território continental responderia a dois elementos: a) competição e necessidade de monopolizar essa área geográfica com tudo o que contem; $b$ ) empreender políticas contra-insurgentes que detenham as capacidades organizativas, as mobilizações e o rechaço à dominação dos povos latino-americanos.

A atual proliferação de bases militares, soldados, equipamentos e forças de inteligência para a América Latina é produto de uma nova concepção estratégica sobre a região, contida na doutrina de segurança nacional estadunidense, nas iniciativas relacionadas com a articulação da força de segurança hemisférica. Essa estratégia intensificou-se especialmente depois do ataque ao Afganistão e à ocupação do Iraque. A estratégia global passa a definir uma doutrina de guerra preventiva que justifica a utilização do poder bélico contra qualquer país, em nome de sua defesa. As novas ameaças estariam ligadas à proliferação de todo tipo de perigo: terrorismo global, crime organizado internacional e narcotráfico mundial que operariam em espaços vazios onde os estados nacionais encontramse desestruturados em seus aparatos repressivos e de inteligência.

${ }^{11}$ Adriana Rossi, "O narcotráfico na estratégia imperial", em Le Monde Diplomatique, julho, 2010, p. 7.

12 Ana Esther Ceceña, "Geopolítica", em Emir Sader [coord.], Latinoamericana. Enciclopédia contemporânea da América Latina e Caribe, São Paulo/Rio de Janeiro, Boitempo Editorial/ Laboratório de Políticas Públicas ueRJ, 2006, pp. 582 y 593. 
Em termos mais concretos, podemos verificar como se desenvolve essa estratégia geral. O Comando Sul norte-americano é o responsável pelo planejamento, coordenação e condução das atividades militares dos Estados Unidos na América Latina e Caribe. Coordena bases militares em diversas regiões da América Latina: Comala (El Salvador), Soto Cano (Honduras), Guantánamo (Cuba), Roosevelt Roads (Porto Rico), Reina Beatriz (Aruba), Hato Rey (Curaçao), Iquitos e Nanay (Peru), Liberia (Costa Rica) e Colômbia. Essas bases militares possibilitam o sobrevôo no espaço aéreo dos países latino-americanos, além de deslocamento por mar e terra. Esse Comando localiza-se em Miami e tem sub sede em Porto Rico. A facilidade com que os militares dos Estados Unidos puderam construir essa rede de bases, de acordo com Petras, ${ }^{13}$ deveu-se principalmente ao apoio e treinamento, em longo prazo, de oficiais militares dos países dependentes, realizado em toda a América Latina. O Comando Sul tem armado, treinado e doutrinado os exércitos nacionais para servirem aos interesses estadunidenses. Desta maneira, evita a utilização de tropas norte-americanas e, assim, reduz a oposição política interna. É um modelo que consiste em dirigir e treinar os exércitos latino-americanos mediante "programas conjuntos", extensivos e intensivos, e subcontratar companhias privadas, que fornecem militares especializados (mercenários).

Os treinamentos conjuntos são periódicos, continuados e envolvem os distintos países, mesmo naqueles com governos originados da esquerda. Entre 2007 e 2009, por exemplo, as Forças Aliadas Panamax envolvendo entre outros Argentina, Brasil, Chile, Colômbia, Equador, Uruguai e Paraguai, realizaram exercícios militares e navais nas Costas do Panamá e Honduras, como também exercícios terrestres na base Soto Cano, Comapala. ${ }^{14}$ Levantamento realizado pela pesquisadora possibilitanos computar que somente no período entre 2007-2010 ocorreram 28 operações de exercícios conjuntos. Isso indica uma crescente organicidade entre as forças armadas dos distintos países latino-americanos com os EU. É necessário observar também que outros países têm participado dessas operações, tais como Canadá, França, Holanda e Reino Unido.

13 James Petras, Império e políticas revolucionárias em América Latina, São Paulo, Xamã, 2002.

${ }^{14}$ Ceceña e outros, El gran Caribe. Umbral de la geopolítica mundial, Quito, Fedaeps/Observatorio Latinoamericano de Geopolítica, 2010, p. 90. 
Nesse sentido, consideramos que a intensificação da militarização como política externa estadunidense é também a continuidade, ao nosso entender, das posições que se apresentavam por exemplo na teoria de contra-insurgência ${ }^{15}$ (1961) e que estará também formulada em documentos do Comitê de Santa Fé ${ }^{16}$ na década de 1980 que orientaram a política externa na região no sentido da aproximação, envolvimento e integração das forças armadas latino-americanas. No entanto, o que podemos considerar que se integra como novo nessa tradição, a partir da década de 1990, é a utilização de empresas privadas con tratistas com mercenários e uma relativa autonomia de atuação que inclusive se sobrepõe aos organismos internacionais e estadunidenses.

Em sua análise sobre o plano estratégico do Comando Sul, Tokatlian observa que tal plano se baseia na eliminação/ausência de instrumentos de mediação institucional - Tratado Interamericano de Assistência Recíproca (TIAR) e a Junta

15 A teoria da contra-insurgência ganhou seus contornos no período de presidência de John F. Kennedy (1961-1963), que propunha reformas sociais nos países latino-americanos, por meio da Aliança para o Progresso. Em realidade, duas faces da mesma moeda para combater a influência política e ideológica do exemplo revolucionário cubano. A teoria da contra-insurgência nos parece fundamental no processo de militarização regional estadunidense porque significou o primeiro momento, em termos sistemáticos e metódicos, da articulação das forças armadas latinoamericanas, não somente em termos ideológicos, mas também como integração subordinada e operacional às orientações do Departamento de Defesa estadunidense. Em reunião com embaixadores latino-americanos, Thomas Mann, então subsecretário de Estado para Assuntos Latino-Americanos, enfatizava que os governos deveriam priorizar sua atenção aos problemas de Segurança Nacional, especialmente protegendo os investimentos norte-americanos e resistindo ao comunismo. Estavam nitidamente apresentados os novos contornos da política externa norteamericana na região. Com o assassinato de Robert Kennedy, cai por terra o "lado humano" da Guerra Fria. Dentro dessa logística de integração militar iniciou-se no período de Richard Nixon (1969-1974) o programa de ajuda em equipamentos militares pesados para policiais e militares latino-americanos, ou seja, a venda de materiais bélicos convencionais.

${ }^{16}$ No período presidencial de Ronald Reagan (1981-1988), um grupo de especialistas em temas latino-americanos e internacionais, designados como falcões —em menção ao símbolo pátrio dos EU- do Partido Republicano, desenvolveram discussões e produziram documentos que assessoraram a política externa de Reagan. O Comitê de Santa Fé, como também conhecido, teve enorme influência nos governos de Reagan, Bush pai e Bush filho. Não deixa de ser simbólica a Cidade de Santa Fé, onde esse grupo se organizou. Cidade mais antiga dos Estados Unidos (1609), localiza-se no Estado de Novo México que foi separado do território mexicano em 1846, junto com Nova Califórnia e o Texas, e integrados formalmente aos EU em 1902. 
Interamericana de Defesa (JID), como também os organismos multilaterais (OEA E ONu). ${ }^{17}$ Para Tokatlian desaparecem as instâncias políticas internas, como Departamentos de Estado, Justiça e Tesouro. Dentro dessa perspectiva o Comando Sul anuncia seu papel e projeção na área para os próximos anos. Tanto a missão como a visão do Comando Sul arrogam-se como organização líder entre as agências existentes para garantir a segurança, a estabilidade e a prosperidade em toda a América. Também se agrega às suas tarefas a coordenação e apoio às coalizões regionais e globais (as coalizões de voluntários) para operações de paz.

Nesse quadro geopolítico foi reativada a IV Frota dos Estados Unidos, desativada em 1950 e reativada em 2008, com circulação no Mar do Caribe e no Atlântico Central e Sul. Ela está subordinada ao Comando Sul estadunidense. De acordo com Osacar, o comandante do Comando Sul, almirante James Stavriids, em visita a Buenos Aires, afirmou que a IV Frota não teria objetivos ofensivos, mas objetivará responder a cinco missões: desastres naturais, operações humanitárias, de assistência médica, contra o narcotráfico e cooperação de assuntos de meio ambiente e tecnologia. ${ }^{18}$ No entanto, não falou da sexta missão, o combate "antiterrorista". Para o analista, a reorganização da IV Frota possivelmente responda a uma estratégia de médio prazo, na qual se visualizam que a América Central e a América do Sul sofram uma intensificação de seus atuais conflitos, os quais poderão escalar até o nível da luta armada, de variada intensidade, com distintas características, em distintas regiões, desenvolvendo-se em forma simultânea e sem que o Brasil não possa ou não queira envolver-se na sua solução.

A coalizão de voluntários propugnada pelo Comando Sul está incorporada como política internacional por países latino-americanos e caribenhos, como ocorreu com a participação militar de El Salvador, Honduras, Nicarágua e República Dominicana na intervenção militar estadunidense no Iraque em 2003, e que teve o apoio da Colômbia e Costa Rica. Outro fato em torno da coalizão de voluntários foi a participação de doze países da área na missão policial-militar

${ }^{17}$ Juan Gabriel Tokatlian, "El militarismo estadounidense en América del Sur", en Le Monde Diplomatique Argentina, núm. 108, junio, 2008, pp. 4-6.

18 Ignacio J. Osacar, "La nueva flota norteamericana por aguas agitadas", en Nueva mayoria.com, 12 de mayo, 2008. 
para manutenção da Ordem Política, mas oficialmente considerada ajuda humanitária, no Haiti, a partir de 2004, entre os quais Brasil e Argentina. Os efeitos gerados nas forças armadas regionais, a partir da concepção e hegemonia do Comando Sul estadunidense, exigem-nos uma análise no sentido de verificar quais impactos políticos e ideológicos de médio prazo estão sendo produzidos nas relações cívico-militares nesses países.

\section{OS NOVOS ACORDOS MILITARES E O EXPANSIONISMO ESTADUNIDENSE NA REGIÃO}

O novo acordo militar ${ }^{19}$ entre Colômbia e EU, assinado em outubro de 2009, ainda que tenha sido suspenso provisoriamente pela Suprema Corte de Justiça colombiana em agosto de 2010, indica não somente a continuidade, mas também o aprofundamento da militarização estadunidense na região andina. O Governo de Colômbia cooperará com os Estados Unidos, continuará permitindo o acesso, uso e ampliação de instalações de bases militares em território colombiano. Para tal fim, os dois governos estabelecerão um mecanismo de coordenação para autorizar o número e categoria das pessoas dos Estados Unidos - empresas privadas contratistas e seus empregados, militares e observadores- e o tipo e quantidade de equipes.

Com o argumento da anulação do contrato da base militar de Manta por Rafael Correa (Equador), os EU em acordo com o governo colombiano ampliaram

19 O primeiro acordo, chamado "Plano para a Paz, a Prosperidade e o Fortalecimento do Estado" (Plano Colômbia), foi aprovado em janeiro de 2001 pelos EU, na gestão do democrata Bill Clinton. O Plano Colômbia foi justificado como um plano de controle e repressão ao narcotráfico e de combate ao terrorismo na região. Esse acordo apresentou-se após a perda da base militar estadunidense no Panamá, em decorrência do acordo entre o Governo Carter e o Governo Omar Torrijos, assinado em agosto de 1977, que teve como eixo a saída estadunidense do território panamenho até o ano de 1999. Por outro lado, o acordo militar colombiano foi assinado após a eleição de Hugo Chávez à presidência da Venezuela, em 1998. Os objetivos foram distribuídos em cinco rubricas: a) pressão para o Sul, nas áreas petrolíferas de Putumayo e Caquetá, com o fornecimento de helicópteros, artilharia, treinamento e assistência nas áreas de inteligência; $b$ ) reforço na interdição na zona andina, apoiando a instalação de radares e bases aéreas e o funcionamento de aviação com melhoria de aeroportos, inclusive Equador, Aruba e Coraçao; $c$ ) apoio aos corpos policiais colombianos; d) desenvolvimento de plantios alternativos à coca; e) melhor governabilidade, com financiamento à captação de representantes para os diálogos de paz. 
para sete as bases militares ${ }^{20}$ no território deste país e projetam a ampliação do número de soldados e mercenários, especialmente na fronteira com a Venezuela. Em documento de maio de 2009, meses antes da assinatura do contrato, o Departamento de Defesa apresentou ao Congresso dos EU as justificativas para reformar uma das bases militares colombianas, ${ }^{21}$ a de Palanquero: "O desenvolvimento dessa csL fornece uma oportunidade única para um espectro completo de operações em uma sub-região crítica de nosso hemisfério, onde a segurança e a estabilidade estão sob a constante ameaça de insurreições narcoterroristas, de governos antiestadunidenses, de uma pobreza endêmica e de constantes desastres naturais". ${ }^{22}$

Não se trata da substituição da base estadunidense de Manta. A ampliação dos aparatos militares em Colômbia não se sustenta com a justificativa de substituição e ainda menos com alguma "constatação" do aumento do crime organizado na Colômbia (narcotráfico) ou ampliação da base territorial dos exércitos revolucionários da FARC e ELn. De acordo com as informações divulgadas pelo governo colombiano e os meios de comunicação internacional dos EU, as derrotas sofridas pelos revolucionários - assassinato de dirigentes e militantes, desestruturação de bases militares e centenas de deserções - indicam pelo menos que não se encontram em ofensiva e, sim, em grande recuo. Então, nesse sentido, cabe a pergunta: onde de fato se localiza o problema de segurança para os EU. Ou as

${ }^{20}$ Palanquero, Malambo, Apiay, Cartagena, Málaga, Larandia, Tolemaida. Os recursos concedidos são da ordem de US\$ 44 milhões para a reforma de Palanquero, à margem do rio Magdalena, região divisa com o território venezuelano. A extensão da área supera três quilômetros e terá capacidade para receber aviões cargueiros C-17 capazes de transportar 70 toneladas e com autonomia de vôo de oito mil quilômetros sem necessidade de reabastecimento. Na região fronteiriça com a Venezuela será criada uma divisão militar com 12 mil homens e uma base na península de Guajira, também fronteira com a Venezuela. Maurice Lemoine, "Os EUA na América Latina. Na mira de Washington”, em Le Monde Diplomatique Brasil, fevereiro, 2010, pp. 6 y 7.

${ }^{21}$ Na terminologia do Pentágono não existem bases militares na América Latina, mas sim postos de operação avançados (FOL-Forwad Operations Location) e postos cooperativos de segurança (CSL-Cooperative Security Locations).

${ }^{22}$ Maurice Lemoine, "Os EUA na América Latina. Na mira de Washington", en Le Monde Diplomatique Brasil, fevereiro, 2010, p. 7. 
FARC de fato não foram derrotadas ou a intensificação da militarização visa um cerco mais intensivo sobre a Venezuela?

A assinatura do acordo militar do Brasil com os Estados Unidos, em abril de 2010, construiu-se em meio a um grande silêncio da mídia brasileira, como também dos setores de movimentos populares e da esquerda política. Esse acordo guarda uma diferença em relação ao acordo militar colombiano. No caso brasileiro não envolve de imediato nenhuma instalação de base militar em seu território, nem reinstalação da base militar de Alcântara (MA). Esse fato político e diplomático apresentou-se com surpresa para muitos, uma vez que o então governo brasileiro ${ }^{23}$ constantemente procura expressar uma postura soberana e independente, como fez transparecer na posição de apoio ao Irã e de diferenciação com a diplomacia estadunidense. De qualquer modo, o governo brasileiro apresenta-se como um grande aliado dos EU na região. No referido Acordo, chama a atenção os aspectos que diretamente se relacionam com participação em treinamento e instrução militar combinados, exercícios militares conjuntos e o intercâmbio de informações relacionado a esse tema, tais como o artigo 1, inciso $d$ : "intercâmbio de instrutores e pessoal de treinamento, assim como de estudantes de instituições militares"; "participação em cursos teóricos e práticos de treinamento, orientações, seminários, conferências, mesas-redondas e simpósios organizados em entidades militares e civis com interesse na Defesa, de comum acordo com as Partes"; "visitas de navios militares". ${ }^{24}$ Certamente novos acordos que se desdobrem do atual devemos esperar, uma vez que abre essa possibilidade no atual acordo.

\section{CONSIDERAÇÕES FINAIS}

A política externa estadunidense mantém seus traços históricos centrais na atualidade sobre a América Latina. As bases militares, os acordos militares, a

23 O acordo foi assinado no último ano de mandato do presidente Luiz Ignácio Lula da Silva (20032010).

${ }^{24}$ Ministério de Relações Exteriores do Brasil, "Brasil-EUA: acordo sobre cooperação de defesa", Brasília, 7 de abril, 2010. Em http://www.itamaraty.gov.br/sala-de-imprensa/notas-a-imprensa/ 2010/04/07/brasil-eua-acordo-sobre-cooperacao-em-defesa/?searchterm = Acordo sobre cooperação de defesa. 
ampliação dos exercícios navais conjuntos, os apoios de inteligência às tentativas de golpes políticos na região, entre inúmeros acontecimentos, permitem-nos evidenciar que existe uma continuidade em sua política externa. Essa tradição que se incorpora nas ações no presente articula-se em circunstâncias distintas e novas.

Essa concepção sintetiza a ambição já presente na expressão "América para os americanos" que, em sua origem no século xix, indicava o que seriam os quase duzentos anos de expansionismo político e militar na região. Uma imagem de integração territorial subordinada aos desígnios imperiais. A expressão é conhecida na Doutrina Monroe (1824). Encontra-se na mensagem do então presidente dos EU, James Monroe, ao Congresso estadunidense considerando o papel desse país como protetor dos países latino-americanos recém emancipados. De caráter defensivo inicialmente, a doutrina tornou-se a principal justificativa intervencionista dos EU no processo de recolonização latinoamericana, na medida em que esse país torna-se potência econômica. O destino manifesto é o momento seguinte que materializava com sua convicta crueldade e etnocentrismo a relação com "nosotros" latino-americanos. Em editorial de periódico de época encontra-se a seguinte formulação: "a pura raça angloamericana está destinada a estender-se por todo o mundo com a força de um tufão", "a raça hispano-mourisca será abatida". ${ }^{25}$ Tal pensamento expressava a autoconfiança e ambição puritana: a idéia de incorporação aos Estados Unidos de todas as regiões adjacentes constituía a realização virtualmente inevitável de uma "missão" moral assinalada à Nação pela Providência.

No quadro sul-americano, a emergência de vários governos na última década permite-nos verificar que não ocorreu um alinhamento automático às políticas norte-americanas. Esse alinhamento tem ocorrido de maneira nítida nos governos colombiano, peruano e chileno. Existe relativa autonomia nos casos brasileiro, boliviano, equatoriano e venezuelano. Nesse último caso, é onde se apresenta uma maior radicalidade discursiva anti-estadunidense, como também onde se loca lizam maiores relações econômicas e militares fora do eixo estadunidense. Cabe

${ }^{25}$ New Orleans Creole Courier, 27/01/1855, apud Voltaire Schilling, Porto Alegre, Mercado Aberto, 1984, p. 13. 
considerar o caso brasileiro, por exemplo, na redefinição da tecnologia militar, como também no posicionamento de apoio ao Irã em relação à sua soberania para o refinamento do urânio, definindo áreas de atrito com a política externa estadunidense. Ao nosso entender, essa relativa autonomia não se apresenta claramente definida, uma vez que esses países mantêm-se orientados pela política de segurança ao narcotráfico e ao terrorismo, ao tempo também que permanecem dentro da novo paradigma de segurança no continente. Talvez se deva pensar o caso venezuelano como mais diferenciado nesse sentido, uma vez que não estabelece acordo militar com os EU e nem se subordina até o presente momento às políticas estadunidenses.

Recibido: 2 de octubre, 2010. Aceptado: 17 de enero, 2011.

\section{REFERÊNCIAS BIBLIOGRÁFICAS}

AYERBE, LuIS FERNANDO, Los Estados Unidos y la América Latina. La construcción de la hegemonía, La Habana, Casa de las Américas, 2001.

BLAIR, Dennis, "Advierten que populismo de Chávez es una amenaza para la región", en El Nacional, 3 de febrero, 2010, p. 9.

Ceceña, Ana Esther, David Barrios, Rodrigo Yedra y Daniel Inclán, El gran Caribe. Umbral de la geopolítica mundial, Quito, Fedaeps/Observatorio Latinoamericano de Geopolítica, 2010, 109 pp.

, "Geopolítica", em Emir Sader [coord.], Latinoamericana. Enciclopéia contemporânea da América Latina e Caribe, São Paulo/Rio de Janeiro, Boitempo Editorial/Laboratório de Políticas Públicas UERJ, 2006, pp. 582 y 593.

Delpirou, Alain y Alain Labrousse, El sendero de la cocaína, Barcelona, Laia, 1988.

Donghi, Tulio Halperin, História da América Latina, São Paulo, Círculo do Livro, 1978, 459 pp. 
Lemoine, Maurice, "Os EUA na América Latina. Na mira de Washington", em Le Monde Diplomatique Brasil, núm. 31, fevereiro, 2010, pp. 6 y 7.

Lopez, Luiz Roberto, História da América Latina, Porto Alegre, Mercado Aberto, 1986, 208 pp.

Brasil, MinistéRIo de Relações Exteriores, "Brasil-EUA: acordo sobre cooperação de defesa", Brasília, 07/04/2010. Em http://www.itamaraty.gov.br/sala-deimprensa/notas-a-imprensa/2010/04/07/brasil-eua-acordo-sobre-cooperacaoem-defesa/?searchterm =Acordo sobre cooperação de defesa.

OSACAR, IGNACIO J., "La nueva flota norteamericana por aguas agitadas", en Nueva mayoria.com, 12 de mayo, 2008.

PeCequilo, Cristina Soreanu, A política externa dos Estados Unidos. Continuidade ou mudança?, Porto Alegre, ufrgs, 2003.

PeTRAS, JAMES, Império e políticas revolucionárias em América Latina, São Paulo, Xamã, 2002, 198 pp.

Rice, CondoleEZZA, Resources for transformational diplomacy, Washington, D. C.,

Statement Before the Senate Appropriations Subcommittee on Foreign Operations. 10 maio, 2007. Em http://www.state.gov/secretary/rm2007/84645.htm. Rodrigues, Thiago, Narcotráfico: uma guerra na guerra, São Paulo, Desatino, 2003.

Rossi, ADRIANA, "O narcotráfico na estratégia imperial", em Le Monde Diplomatique Brasil, núm. 36, julho, 2010, p. 7.

SCHILING, VolTAIRE, Estados Unidos versus América Latina. As etapas da domi nação, Porto Alegre, Mercado Aberto, 1984, 180 pp.

Silva, Luiz Fernando DA, "Ajustes neoliberais e lutas sociais: estratégias políticas na América Latina", em Marxismo Vivo. Revista de Teoria e Política Internacional, núm. 13, 2006. pp. 8-14.

TOKATLIAN, JuAn Gabriel, "El militarismo estadounidense en América del Sur", en Le Monde Diplomatique Argentina, núm. 108, junio, 2008, pp. 4-6.

, "Post 11/9. Después de Afganistán y em médio de Irak: una desorden de seguridad sudamericano?", em Joseph S. Tulchin [coord.], El rompecabezas. Conformando la seguridad hemisférica en el siglo XXI, Buenos Aires, Prometeo Libros/Bononia e Libris, 2006, 534 pp. 